\title{
O BNDES E A SUSTENTAÇÃO RECENTE DO SETOR SUCROENERGÉTICO BRASILEIRO (2002-2015)
}

Laís Ribeiro Silva ${ }^{1}$

Mirlei Fachini Vicente Pereira²

Resumo: historicamente o Estado brasileiro sempre figurou como agente central para sustentação do setor sucroenergético (produção de cana-de-açúcar e seus derivados), acionando diferentes políticas e recursos em diversos períodos. Particularmente entre os anos 2000 e 2015, o BNDES (Banco Nacional de Desenvolvimento Econômico e Social) atuou de modo central para a sustentação do setor, através de financiamentos em diversas áreas essenciais à produção: infraestrutura, logística, capital de giro, pesquisa, plantio entre outros. Uma análise detalhada dos dados de financiamento do BNDES para o setor sucroenergético neste período permite compreender quais agentes foram beneficiados e quais implicações territoriais e políticas esse cenário apresenta. Nesse artigo espera-se demonstrar, de modo sistematizado, como se deu a atuação recente do BNDES e, deste modo, do próprio Estado brasileiro, para o setor sucroenergético e como tal situação revela as circunstâncias do uso do território no Brasil pelo referido setor.

Palavras-chave: Setor Sucroenergético; BNDES; Uso do território; Brasil

\section{THE NATIONAL BANK FOR ECONOMIC AND SOCIAL DEVELOPMENT (BANCO NACIONAL DE DESENVOLVIMENTO ECONÔMICO E SOCIAL - BNDES) AND THE RECENT SUPPORT OF BRAZILIAN SUGARCANE SECTOR (2002-2015)}

\begin{abstract}
Brazilian State has always been a central agent to support the sugar-energy sector (sugarcane production and its derivatives), activating different policies and resources in distinct periods. Particularly between 2000 and 2015, the BNDES (Banco Nacional de Desenvolvimento Econômico e Social) was central to support the sector through financing in diverse areas crucial to production: infrastructure, logistics, working capital, research, planting among others. A detailed analysis of the BNDES financing data for the sugar-energy sector in this period allows us to understand which agents received benefits and what territorial and political implications this scenario presents. This article expects to demonstrate, in a systematized way, how the recent performance of the BNDES and, thus, the Brazilian State itself, for the sugar-energy sector has occur and how this situation reveals the circumstances of the use of the territory in Brazil by the this sector.
\end{abstract}

Keywords: Sugar-energy Sector; BNDES; Use of Territory; Brazil

\footnotetext{
1Universidade Federal de Uberlândia, Instituto de Geografia, Uberlândia, Brasil, silva.laisrs@gmail.com, https://orcid.org/0000-0001-7840-8821

2 Universidade Federal de Uberlândia, Instituto de Geografia, Uberlândia, Brasil, mirlei@ufu.br, https://orcid.org/0000-0002-1094-8829
} 


\section{EL BANCO NACIONAL DE DESARROLLO ECONÓMICO Y SOCIAL (BNDES) Y LA SUSTENTACIÓN RECIENTE DEL SECTOR SUCROENERGÉTICO EN BRASIL (2002-2015)}

Resumen: en Brasil, el sector sucroenergético (producción de caña de azúcar y sus derivados), es históricamente sostenido por políticas estatales. En particular, entre los años 2000 y 2015, el Banco Nacional de Desarrollo Económico y Social (BNDES) actuó de modo fundamental para la producción, la sustentación del sector, a través de financiamientos en diversas áreas esenciales a la producción: infraestructura, logística, capital de giro, investigación, plantación, entre otros. Un análisis detallado de los datos de financiamiento público, a través del BNDES, para el sector sucroenergético en este período, permite comprender qué agentes fueron beneficiados y cuáles implicaciones territoriales y políticas resultaron directamente de esa situación. Se espera con este texto demostrar, de modo sistematizado, cómo ocurrió la actuación reciente del BNDES y, de este modo, del propio Estado brasileño, para el sector sucroenergético y como tal situación revela las circunstancias del uso del territorio brasileño por este sector.

Palabras clave: Sector Sucroenergético; BNDES; Uso del territorio; Brasil

\section{Introdução}

Em que pese a existência de traços e características gerais, o desenvolvimento do capitalismo comporta, em cada formação socioespacial, particularidades e nuances que permitem reconhecermos estratégias e características particulares da acumulação capitalista nos diferentes países do mundo. O Brasil aparece como nítido exemplo de como o Estado historicamente atuou como agente central na economia, seja de modo direto, a partir de ações centralizadas e voltadas ao investimento estatal em determinados setores, seja de modo indireto (mas ainda fundamental), a partir de financiamento público de atividades econômicas coordenadas pela esfera privada, como parece ser o caso nesta fase atual de neoliberalismo sob predomínio do capital financeiro.

Assim, a intenção do presente texto é avaliar como o Estado brasileiro figurou como agente essencial para a manutenção e competitividade das atividades relacionadas ao cultivo e processamento de cana-de-açúcar, atuando de diversas formas em diferentes períodos. Através da norma e da técnica, o Estado brasileiro interferiu nas formas de uso do território, o que ocorreu para as atividades da canade-açúcar desde o período colonial.

Especialmente após os anos 2000, novas condicionantes emergem para o setor, que inclusive, passa a ser chamado de "sucroenergético", decorrente dos 
novos subprodutos possíveis (energia elétrica e combustível), que se constituem como novas demandas de mercado. Também nesse momento, o Estado passou operar de modo distinto, fornecendo as bases para a expansão das atividades através de concessões, de financiamentos e de ofertas de crédito subsidiado, além da materialidade necessária à fluidez da produção. Através desse processo, é possível pensar na centralidade do Estado na otimização capitalista do uso do território, processo este muito ancorado no emprego de recursos públicos, por meio da constituição de uma materialidade direcionada a objetivos e interesses específicos.

Uma forma específica por meio da qual o Estado ofereceu suporte às atividades sucroenergéticas no período analisado (2002-2015), são as operações de financiamento subsidiado ofertadas pelo Banco Nacional do Desenvolvimento Econômico e Social (BNDES). Os resultados da análise desse instrumento de intervenção do Estado, no período supracitado, bem como algumas reflexões possíveis a partir dos dados, encontram-se sintetizados nesse artigo.

Em termos metodológicos, destacamos o levantamento de dados a partir de informações do BNDES em um conjunto de planilhas disponibilizadas pela instituição, onde consta a totalidade das operações de financiamento realizadas pelo Banco entre os anos de 2002 e 2015 (que podem ser acessadas na seção de transparência do BNDES). O processo de tratamento dos dados constituiu, primeiramente, na seleção das operações que incluíam agentes ou etapas produtivas específicas do setor sucroenergético, com posterior classificação, de acordo com o tipo de projeto financiado. Demais classificações foram realizadas posteriormente, detalhando os tipos de agentes receptores $e$ as unidades federativas em que se encontram localizados. Ademais, a metodologia também incluiu levantamentos e leitura de bibliografias temáticas (acerca das práticas do setor sucroenergético no país) e teórico conceituais da geografia (as quais foram tencionadas à situação empírica avaliada).

Para além desta introdução e de algumas considerações finais, o texto encontra-se dividido em três seções. A primeira seção recupera, brevemente, a histórica relação entre o Estado brasileiro e o setor sucroenergético, apontando as políticas que, em diferentes períodos, revelam o substancial amparo do estado ao funcionamento do setor no país. A segunda seção avalia a função substancial que o BNDES desempenhou junto ao setor sucroenergético a partir do início do século 
atual, quando o mesmo conhece significativa expansão no território brasileiro e ganha novos contornos territoriais e novos agentes. A terceira e última seção apresenta uma tipologia dos projetos financiados pelo Estado brasileiro ao setor via BNDES, bem como os principais agentes beneficiados, revelando o caráter corporativo e concentrado da destinação dos recursos.

\section{Breve histórico da relação entre o setor sucroenergético e o Estado no Brasil}

O processo histórico que configurou a situação atual do setor sucroenergético brasileiro releva o Estado como figura central que, de diferentes formas, sempre atuou para a sua sustentação. Através de uma análise que considere a totalidade das relações entre política e técnica (SANTOS, 2004, 2012), torna-se possível uma proposta de periodização da dinâmica dos usos do território pelos agentes do setor sucroenergético, constituída, grosso modo, por quatro diferentes períodos (SILVA, 2017).

O primeiro período, que também é o mais extenso, se estendeu do início das atividades açucareiras no Brasil colonial até as primeiras décadas do século $X X$, e se caracterizou por um meio técnico incipiente, com emprego de técnicas rudimentares e produção praticamente artesanal do açúcar (concentrada principalmente no espaço que corresponde à atual Região Nordeste do país). 0 segundo período se estendeu da década de 1930 até os anos 1970 e foi marcado por uma forma variada de centralidade do Estado na condução da produção açucareira, com a criação do Instituto do Açúcar e do Álcool (IAA) em 1933 e pela emergência da usina como objeto técnico que passa a ser predominante na produção, e que estabelece a possibilidade de separação entre o controle do processo produtivo e do industrial. Esse período também foi marcado por mudanças políticas e econômicas, como o contexto de superprodução de açúcar, a transferência dos excedentes exportáveis para o mercado interno (que se afirma neste momento) e a mudança do eixo produtivo da atual Região Nordeste para o Sudeste (SZMRECSÁNYI, 1979, p. 161 et seq.).

Em 1975, com a criação do Programa Nacional do Álcool (Proálcool), durante o regime militar, inicia-se um terceiro período, muito significativo para as atividades sucroenergéticas (ANDRADE, 2006, p. 62), quando a atual Região Sudeste definitivamente passa a ser a principal responsável pela produção brasileira de 
açúcar e álcool. Foi com o Proálcool que a fabricação de combustível automotivo derivado de cana-de-açúcar se consolidou no Brasil, uma vez que o programa teve como propósito tornar o álcool o principal combustível nacional, num contexto de aumento significativo do preço do petróleo nos anos 1970. Esse terceiro período se extingue nos anos 1990, quando também se encerra as políticas mantidas pelo Proálcool, num contexto de desregulamentação do mercado e inserção de políticas neoliberais no Brasil.

A década de 1990 abarcou a transição de um período marcado pela intensa intervenção estatal do período militar, para outro, marcado pelas demandas do próprio setor, que defende a diminuição do poder do Estado, bem como pela abertura econômica dos governos Itamar Franco e Fernando Henrique Cardoso, orientados pela inserção recente dos ideais neoliberais na América Latina como um todo (TEIXEIRA, 1998, p. 225; DELGADO, 2010, p. 80-84). Para o setor sucroenergético esse período significou um certo absenteísmo do Estado, se comparado com os períodos anteriores. Foi apenas com o início dos anos 2000, quando o Brasil como um todo passou por transformações de ordem política, econômica e social, que uma reestruturação das atividades produtivas da cana-deaçúcar se iniciou, inclusive no que diz respeito a distribuição espacial da produção agrícola e industrial, inaugurando um novo modelo de suporte político-estatal à atividade e também um novo período para o setor sucroenergético.

Novas orientações políticas e econômicas surgiram nesse período, especialmente através dos governos do Partido dos Trabalhadores (2003-2016), a partir de certo retorno da centralidade e do papel do Estado em setores tidos como estratégicos, que, em novos moldes, passou a influenciar a dinâmica das atividades sucroenergéticas através de financiamentos em infraestrutura produtiva e logística, e na execução de políticas públicas de interesse do setor (CAMELINI; CASTILLO, 2012, p. 10). Trata-se de um processo de viabilização de recursos e do território, orquestrada pelo Estado por intermédio de recursos públicos, com fins de sustentação de um setor específico da economia, visto como estratégico para o país. Esse processo resulta na materialização de um denso sistema de objetos técnicos, oriundo de esforços e recursos públicos, cujo uso se dará na esfera privada, configurando novas características ao uso corporativo do território (SANTOS, SILVEIRA, 2001). 
Nesse período houve um processo de crescimento do setor e decorrente expansão territorial das atividades para outras áreas do Sudeste e para o CentroOeste do país (devido a características intrínsecas do processo produtivo da canade-açúcar) onde novos espaços agrícolas brasileiros foram acionados para participarem do processo produtivo (CASTILLO, 2015, p. 97). Em termos quantitativos esse crescimento significou a passagem de 326,12 milhões de toneladas produzidas em 2000 para 768,6 milhões em 2016, e um aumento de mais de $200 \%$ na área plantada em hectares no país (SIDRA/IBGE, 2018). Houve também a crescente participação de agentes estrangeiros na atividade sucroenergética (vide o número de fusões e aquisições realizadas por grandes holdings do agronegócio, como a Cargill, ADM, Louis Dreyfus Commodities, etc.) que aparentemente encontraram, no contexto de crise financeira internacional, possibilidades de lucro com a exploração de novos negócios voltados às chamadas flex crops (culturas flex) (BORRAS JR et al., 2015.), somado a conjuntura de políticas anticíclicas (TEIXEIRA, PINTO, 2012, p. 923) e a consequente oferta de fartos financiamentos do Banco Nacional do Desenvolvimento Econômico e Social (BNDES) no Brasil.

A instrumentalização do BNDES se configurou, nesse contexto, como um modo essencial de operacionalização do apoio do Estado ao setor e a sua expansão. Assim, torna-se necessário compreender a principal forma de atuação do BNDES, que são os financiamentos subsidiados, bem como quais agentes e porções do território são beneficiadas por esse processo, o que contribui, ao final, para a compreensão da conformação atual (pós anos 2000) do setor sucroenergético.

\section{A estruturação e efetivação dos financiamentos do BNDES para o setor sucroenergético brasileiro}

Por meio da configuração de um conjunto de normas, o Estado consegue intervir e direcionar a materialidade do território, viabilizando-o para diferentes interesses. Nesse sentido, as transformações materiais no território decorrentes das ações do Estado representam constante conflitualidade de interesses em sua própria configuração. Não somente o papel do Estado, mas também de variados agentes, pode ser elucidado através da perspectiva de território usado 
(BERNARDES et al., 2000, p. 12). Isso significa pensar o território através de seus usos sociais, ou seja, dos usos efetivamente realizados, que, por sua vez, implicam na permanente elaboração e reelaboração de uma base ao mesmo tempo material e social das ações humanas, que apresenta diferentes situações em cada momento histórico.

Para Santos e Silveira (2001), quando ocorre a viabilização do território pelo Estado para um interesse privado específico, tem-se a conformação de uma situação de uso corporativo do território. Isso se dá através do direcionamento de capital público para a criação de infraestruturas e empreendimentos diversos que respondem a interesses específicos.

Para os atores hegemônicos o território usado é um recurso, garantia da realização de seus interesses particulares. Desse modo, 0 rebatimento de suas ações conduz a uma constante adaptação de seu uso, com a adição de uma materialidade funcional ao exercício das atividades exógenas ao lugar, aprofundando a divisão social e territorial do trabalho, mediante a seletividade dos investimentos econômicos que gera um uso corporativo do território (BERNARDES et al., 2000, p. 12).

A partir dessa organização, o conteúdo técnico do território permite, em algumas porções do espaço, a comunicação constante e precisa entre os agentes (SANTOS, 2012, p. 265). O território revela-se, nesse contexto, funcional às necessidades de agentes específicos e torna-se um meio para o exercício do poder daqueles que dispõem de técnica, estruturas, bens, conhecimentos, recursos e pessoas (KAHIL, 2010). De modo geral, essa funcionalização acontece com incentivos e uso de recursos públicos que, ao final, solidificam infraestruturas corporativas, pois nascem com finalidades e intenções de uso específicas e prédeterminadas, cujo acesso se dá forma desigual entre os agentes.

Para compreender a viabilização do território pelo Estado para o setor sucroenergético após os anos 2000, deve-se considerar como fundamental as atividades de financiamento exercidas pelo BNDES. De modo geral, desde sua criação em 1952, o BNDES historicamente demonstrou-se como instrumento de ação do Estado em favor aos interesses corporativos, seja através dos financiamentos diretos ou da sua participação na viabilização do território para o processo de reprodução capitalista (OLIVEIRA, 2003). 
A partir dos anos 1930, segundo Oliveira (2003, p. 35-36), houve no Brasil a instauração de um novo padrão de desenvolvimento que favoreceu o capital industrial (representado principalmente pelas indústrias de bens duráveis e pela agroindústria), que muito difere do momento anterior, em que predominava no Brasil o capital agrário exportador. O modelo industrial de acumulação encontrou uma série de adversidades para se concretizar no Brasil devido as condições históricas do período em que se afirmou (mercado de trabalho inadequado, ausência de setor financeiro para sustentar o processo e ausência de um setor produtor de bens de consumo e insumos básicos para a indústria - máquinas, equipamentos, infraestrutura).

A resolução desses problemas ocorreu com a concretização de um pacto político entre Estado e elites, no processo de modernização conservadora, em que o Estado assumiu as responsabilidades de criação das condições de reprodução capitalista no Brasil através de processos como incentivo às exportações, às importações de insumos, máquinas e equipamentos para produção interna, e criação de estatais para a implantação de importantes macroestruturas técnicas necessárias às atividades produtivas, como energia, telecomunicações, siderurgia etc. (TEIXEIRA, 1998, p. 219). Tratou-se de um padrão de ação do Estado brasileiro que consistiu na criação das condições territoriais de reprodução do capital.

Nesse contexto criou-se o BNDES, na época denominado Banco Nacional do Desenvolvimento Econômico (BNDE), fundado por meio da Lei no 1.628 de 20 de junho de 1952, que tinha como objetivo gerir essas mudanças necessárias para a modernização do território brasileiro (CORRÊA, 1995). Assim, pode-se dizer que desde o início o BNDES foi um importante instrumento para a viabilização do território, das atividades produtivas e da execução de projetos de desenvolvimento, sempre se ajustando às transformações e dinâmicas do padrão de desenvolvimento brasileiro (CORRÊA, 1995; FARIAS, 2013).

A partir de 1999, e plenamente inserido num contexto de aprofundamento das políticas neoliberais no Brasil, as ações de financiamento do BNDES responderam as condicionantes do modelo de crescimento pautado na exportação de commodities minerais e agrícolas, indicativo do novo pacto da economia política do agronegócio, tal como avaliou Delgado (2012). Assim, e particularmente após 2003 (e já sob o mandato do Partido dos Trabalhadores) os financiamentos do BNDES aumentaram consideravelmente, pautados na ampliação da capacidade de 
produção, circulação, armazenagem e escoamento (infraestrutura e logística) dos "setores estratégicos" da economia brasileira, ou seja, o agronegócio, a mineração, a exploração de petróleo e a construção civil (VEGA; RODRIGUEZ, 2015, p. 93).

Especificamente para o setor sucroenergético, a base dos financiamentos realizados pelo BNDES no período aqui analisado (2002-2015) voltou-se à construção e/ou expansão de unidades produtivas. No entanto, ocorreram também ações de financiamento em pesquisas científicas, renovação de canaviais, criação de infraestruturas diversas, logística e capital de giro.

Os financiamentos do BNDES ${ }^{3}$ para as atividades sucroenergéticas foram, a partir de então, consideráveis, e se realizam via programas criados especificamente para o setor. Até 2015, existiam duas linhas principais de financiamento para o setor e que merecem destaque: o Programa de Apoio à Renovação e Implantação de Novos Canaviais (BNDES Prorenova) e o Programa de Apoio ao Setor Sucroenergético (BNDES Pass) ${ }^{4}$. O Prorenova oferece financiamento de todos os itens relacionados ao processo de renovação e implantação de novos canaviais, o que é essencial para a continuidade da produção e manutenção da produtividade agrícola das áreas cultivadas. O programa se divide em dois segmentos, 0 Prorenova Rural e o Industrial, onde o primeiro abrange produtores ou cooperativas produtoras de cana-de-açúcar e o segundo se destina a pessoas jurídicas que se ocupam da produção de açúcar, etanol e derivados (usinas, destilarias e também cooperativas). O BNDES Pass, por sua vez, se destina a financiar o processo de estocagem de etanol, e está disponível para todas as usinas, destilarias, cooperativas de produtores e empresas de comercialização de etanol cadastradas

\footnotetext{
${ }^{3}$ O BNDES possui como atuais fontes de recursos a arrecadação dos tributos do Fundo de Amparo ao Trabalhador (FAT), Programa de Integração Social (PIS) / Programa de Formação do Patrimônio do Servidor Público (PASEP) e Tesouro Nacional sendo estes dois últimos, sua fonte principal de auxílios. Além destas fontes, recursos de outras origens também são utilizados em menor escala para compor o fundo financeiro do BNDES, como: Fundo da Marinha Mercante, Fundo de Investimentos do Fundo de Garantia do Tempo de Serviço (FI-FGTS) títulos no mercado externo e empréstimos em bancos estrangeiros. Para se ter uma ideia, entre 2010 e 2015 o Tesouro Nacional proveu entre $46 \%$ e $57 \%$ e o PIS-PASEP entre $26 \%$ e $29 \%$ dos recursos (BNDES, 2015).

4 Tais programas de financiamento não se destinam a todas as regiões do país, sendo circunscrito aos seguintes grupos: Grupo 1 - Centro-Oeste, Sul e Sudeste, aos estados do Ceará, Maranhão, Pará, Piauí e Tocantins; e especificamente aos municípios de Juazeiro e Medeiros Neto, ambos no estado da Bahia; e Grupo 2 - Alagoas, Paraíba, Pernambuco, Rio Grande do Norte, Sergipe e Bahia (com exceção dos municípios citados no Grupo 1). O valor máximo de financiamento é de até $R \$ 500$ milhões por cliente. O orçamento de 2014 , para os dois programas, foi estipulado em $R \$ 5$ bilhões, sendo que o BNDES Pass ultrapassou do teto de financiamento de $R \$ 1$ bilhão em 2013 para $R \$ 2$ bilhões em 2014 (BNDES, 2015).
} 
na Agência Nacional de Petróleo, Gás Natural e Biocombustíveis (ANP) (BNDES, 2015).

Ainda existem outros programas do BNDES específicos para o setor sucroenergético, como o Programa de Apoio à Inovação Tecnológica Industrial dos Setores Sucroenergético e Sucroquímico (PAISS), que possui uma versão específica para a etapa agrícola da produção ${ }^{5}$.

O PAISS Agrícola, que como a denominação indica é direcionado especificamente para a etapa agrícola da produção, custeia projetos de desenvolvimento de novas variedades de cana-de-açúcar, atividades de melhoramento genético, sistemas integrados de manejo, novas técnicas de propagação de mudas entre outros. Lançado em 2014, era previsto que até 2018 fossem custeados $R \$ 1,48$ bilhões em projetos no âmbito do programa. Desse montante, $\mathrm{R} \$ 80$ milhões seriam provenientes de um fundo de recursos não reembolsáveis, usualmente direcionados a instituições de pesquisa ${ }^{6}$. No entanto, em 2014 o BNDES divulgou que os 35 projetos até então aprovados no PAISS Agrícola já somavam $R \$ 1,9$ bilhões, superando a meta inicial do Programa em quase $30 \%$ (BNDES, 2015).

A aquisição de equipamentos e outros investimentos relacionados a modernização e expansão da capacidade produtiva também pode ser realizada através de outros programas do BNDES não exclusivos para 0 setor sucroenergético, como é o caso do BNDES Finem. Nesse programa existe uma linha específica de financiamento, a "Linha de apoio a Agropecuária", contemplando o segmento "Agropecuária 2", que regula o financiamento de equipamento para o setor sucroenergético, além da implantação e renovação de canaviais (BNDES, 2015).

\footnotetext{
${ }^{5}$ O PAISS é uma resolução conjunta do BNDES e da Financiadora de Estudos e Projetos (FINEP), empresa pública de fomento à ciência, tecnologia e inovação. Através de uma ação conjunta, essas instituições selecionam para fomento planos de negócios relacionados ao desenvolvimento, a produção e a comercialização de novas tecnologias industriais destinadas ao processamento da biomassa oriunda da cana-de-açúcar. São três linhas temáticas para enquadramento dos projetos possíveis de financiamento: 1) bioetanol de segunda geração; 2) novos produtos de cana-de-açúcar e; 3) gaseificação: tecnologias, equipamentos, processos e catalizadores (BNDES, 2015).

6 Alguns exemplos de instituições de pesquisa contempladas por recursos não reembolsáveis do BNDES entre 2002 e 2015 foram a Fundação de Apoio à Pesquisa Científica e Tecnológica do Distrito Federal, Centro Nacional de Pesquisa em Energia e Materiais, Fundação de Amparo à Pesquisa do Estado de São Paulo, entre outras.
} 
A existência e as condições desses programas elucidam a intenção do Estado brasileiro em viabilizar as atividades do setor sucroenergético no território, nesse caso, via instrumentalização do BNDES.

A análise dos dados de financiamentos (operações indiretas e diretas ${ }^{7}$ ) do BNDES ocorridos entre 2002 e 2015 demonstra um significativo aporte de recursos, o que permite inferir a centralidade do BNDES como mecanismo que permite ao Estado atender as demandas corporativas do setor sucroenergético.

Os financiamentos do BNDES no período (Gráfico 1) se concentraram na renovação ou plantio de novos canaviais, financiamento de capital de giro, pesquisa, logística e instalação de novas unidades produtivas e/ou expansão das já existentes. Há ainda que se destacar o financiamento à construção de cogeradores de energia elétrica a partir do bagaço da cana-de-açúcar, recentemente estimulada pela possibilidade de comercialização dos excedentes de eletricidade produzida nas usinas sucroenergéticas.

\section{Gráfico 1. Investimentos do BNDES voltados ao setor sucroenergético (2002 - 2015)}

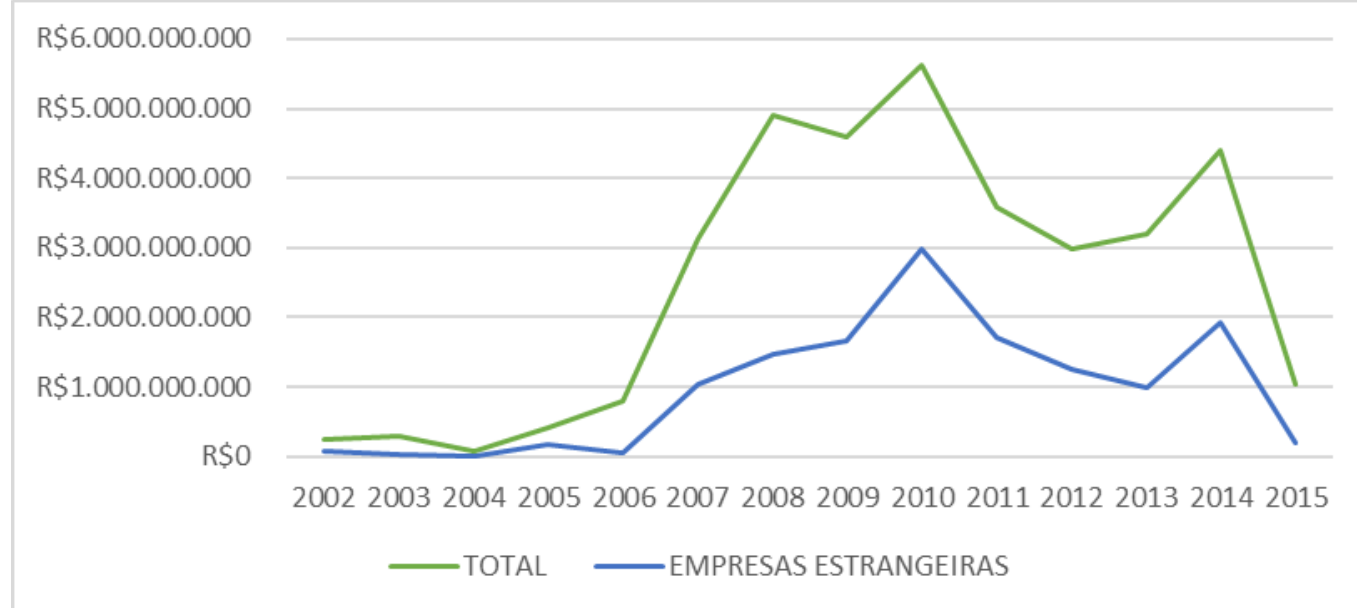

Fonte: BNDES, 2017.

\footnotetext{
${ }^{7} \mathrm{Na}$ esfera processual, as operações de financiamento do BNDES ocorrem de duas formas distintas: operações diretas e operações indiretas. As operações diretas dizem respeito aos financiamentos superiores a $\mathrm{R} \$ 20$ milhões e que necessitam passar por uma análise prévia do próprio banco, realizada através de uma série de documentos que precisam ser entregues ao banco com características e informações gerais sobre o projeto a ser financiado. As operações indiretas são aquelas realizadas por intermédio de uma instituição financeira credenciada ao BNDES, que assume por si só os riscos da operação e pode então impor os limites que achar necessário para concretizar um financiamento. As operações indiretas podem ainda ser automáticas, e assim não precisam passar por uma avaliação prévia do BNDES, ou não-automáticas, que ao contrário, precisam passar uma avaliação (BNDES, 2015).
} 
A partir do gráfico, percebe-se que houve um aumento significativo dos investimentos do BNDES entre 2006 e 2010, com uma crescente disponibilização de recursos, que triplicou nesse período, o que foi também acompanhado pelo crescimento do número de usinas, que passou de 352 em 2006 para 390 em 2014, além do aumento da produção de cana-de-açúcar já referido (SIDRA/IBGE, 2015). Também durante o referido período, a designação de recursos para as empresas estrangeiras compôs aproximadamente $40 \%$ do total de recursos destinados pelo BNDES, o que representou mais de $R \$ 13,6$ bilhões, de um total de quase $R \$ 34$ bilhões investidos no setor (BNDES, 2015).

Assim, pode-se dizer que entre 2006 e 2010, o aumento dos investimentos do BNDES se relacionou a uma expansão das atividades produtivas que incluiu também agentes estrangeiros. Trata-se então de uma sustentação do setor pelo Estado brasileiro, que incluiu tanto novos agentes (em sua maioria estrangeiros), que entram no setor como forma de diversificar seus capitais em um momento de crise financeira e de liquidez internacional, quanto agentes nacionais consolidados. No entanto, essa sustentação apresenta limites que podem ser percebidos pela queda nos investimentos entre 2010 e 2015, que coincidiu com um período de fechamento de usinas, resultante de problemas climáticos, perda da competitividade do etanol e crescimento das dívidas decorrente da crise financeira internacional de 2018.

É possível pensar na hipótese de que o aumento dos investimentos até 2010 se relacionou com a conjuntura das pautas ambientalistas (institucionalizadas no Protocolo de Kyoto), da estratégia do governo brasileiro e de empresas, do fortalecimento do etanol como commodity global, e, logo, como nova frente de acumulação que se desenhava até o momento da crise financeira.

De todo modo, a análise das atividades de financiamento do BNDES torna evidente os esforços estatais que são voltados para a viabilização de interesses corporativos (inclusive de agentes externos), muitas vezes descompromissados com a sociedade e com o território. Trata-se de uma subordinação do poder público às lógicas do mercado, cada vez mais globalizado e comandado pelos grandes grupos econômicos (GENNARI, 2002). Como advertem Santos e Silveira,

A serviço de grandes empresas privadas, o território nacional conhece, em certos lugares, uma adequação técnica e política que permite a tais empresas uma produtividade e um lucro maiores. Em 
última análise, trata-se de uma racionalidade privada obtida com recursos públicos. Em outras palavras, tal racionalidade representa sempre uma drenagem de recursos sociais para a esfera do setor privado (SANTOS, SILVEIRA, 2011 p. 272).

Para Santos e Silveira (2011) trata-se de uma nova relação que se estabelece no período de globalização: a do uso privativo do território, em que este, por intermédio do Estado, encontra-se submetido a lógica das grandes empresas, ou seja, a lógica do mercado global (SANTOS; SILVEIRA, 2011). Tal como ocorre no setor sucroenergético, essa viabilização de recursos e do território é em geral executada por intermédio de recursos públicos que, ao final, geram uma materialidade cujo uso é privado.

\section{Tipos de projetos financiados e agentes beneficiados}

Entre 2002 e 2015, foram realizadas 16.730 operações de financiamento pelo BNDES, sendo que 1.532 (9,15\% das operações) foram exclusivas para o setor sucroenergético, representando um montante de $\mathrm{R} \$ 33,948$ bilhões em um universo total de $\mathrm{R} \$ 747,214$ bilhões (total de investimentos do BNDES no período). Esse percentual de exclusividade é significativo, tendo em vista o BNDES atua em quase todos os setores da economia ${ }^{8}$. Colocado em perspectiva esse montante é alarmante - apenas como exemplo e em termos comparativos, segundo dados do Ministério da Fazenda, organizados pelo Conselho Federal de Medicina, entre 2001 e 2013, os repasses federais para a saúde somaram $R \$ 33,0$ bilhões (CFM, 2014), portanto, menor do que os repasses disponibilizados às atividades sucroenergéticas.

Com objetivo de sistematizar e analisar os dados levantados, dividimos as operações de financiamento do BNDES para o setor em sete categorias, cujos percentuais de investimentos podem ser observados no gráfico abaixo (Gráfico 2):

\footnotetext{
${ }^{8}$ Os únicos setores/empreendimentos não passíveis de financiamento são os seguintes: comércio de armas, motéis, saunas, termas, jogos de prognósticos e semelhados e atividades bancárias (com ressalvas para o apoio ao microcrédito) (BNDES, 2015).
} 


\section{Gráfico 2. Distribuição percentual dos investimentos do BNDES por categoria (2002-2015)}

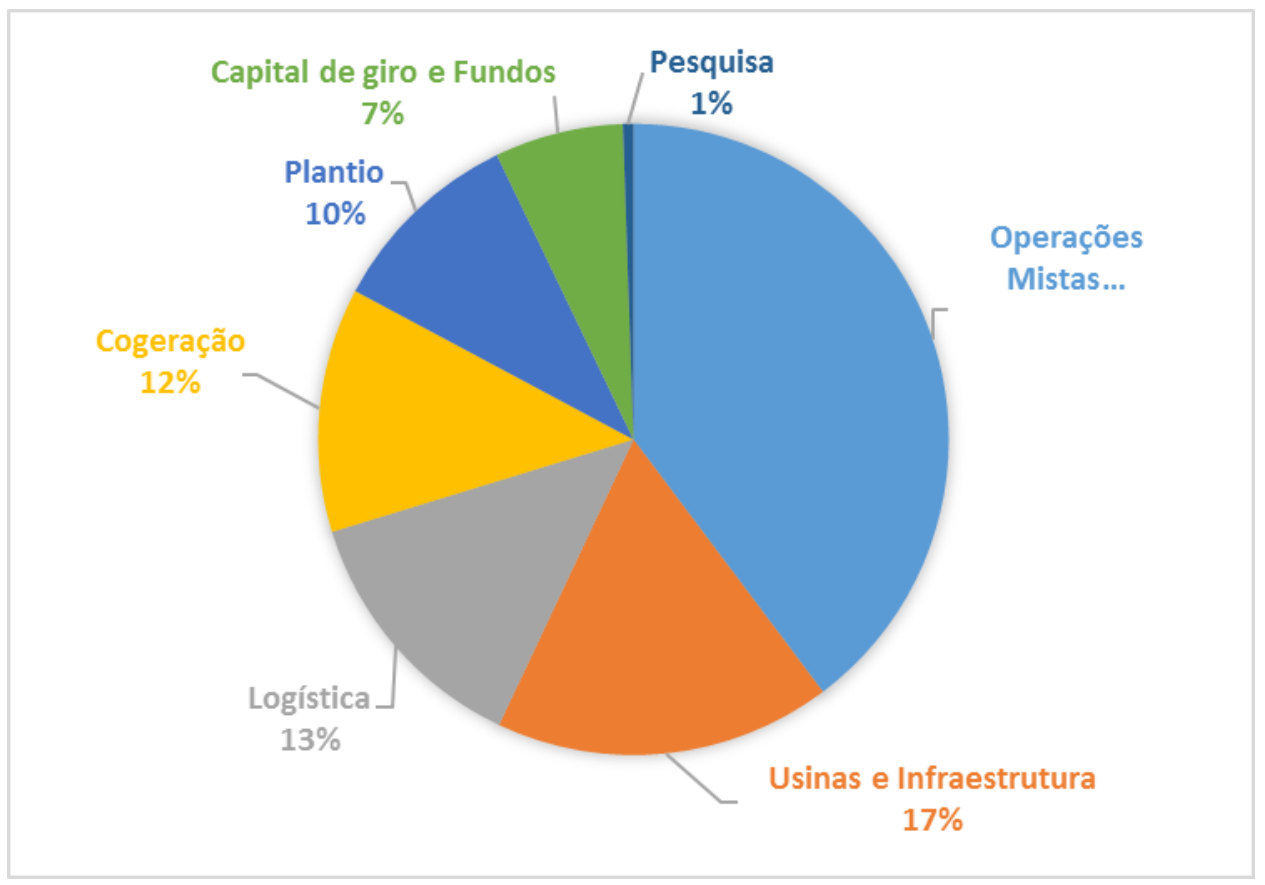

Fonte: BNDES, 2017.

A categoria "operações mistas" agrega a maior parte das operações e é composta por aquelas que não podem ser direcionadas à alguma categoria específica, uma vez que possuem variação de projetos dentro de uma mesma operação (modo pelo qual os dados são divulgados pelo BNDES). Na categoria "usinas/infraestruturas" se encaixam as operações que abrangem projetos de expansão de unidades produtivas ou instalação de novas unidades e de mecanização agrícola, exceto os projetos que envolvem somente cogeração de energia ("categoria cogeração"). A categoria "plantio" compreende os projetos de plantio e reforma de canaviais e a categoria "logística" diz respeito as operações de financiamento das redes técnicas que permitem a distribuição do que é produzido. A categoria "capital de giro e fundos" corresponde as operações de investimentos que não apresentam projetos definidos e que visam constituir capital de giro das empresas. A categoria "pesquisa" abrange as operações de financiamento e pesquisa voltadas para o setor e realizadas sobretudo por órgãos públicos, como universidades e institutos de pesquisa, e constituem a parte de recursos não 
reembolsáveis. As principais empresas ${ }^{9}$ financiadas (Tabela 1), que nesse contexto são de origem nacional e após o ano 2000 passam a contar com participação ativa de capitais estrangeiros através de abertura ao mercado financeiro e do contexto de liquidez internacional, bem como os valores absolutos disponibilizados em cada uma das categorias (Tabela 2) podem ser conferidos nas tabelas a seguir.

Tabela 1. Principais empresas do setor sucroenergético financiadas pelo BNDES em valores totais e percentual do total de investimentos (2002-2015)

\begin{tabular}{ccc}
\hline Empresa & Repasse em R\$ & $\%$ \\
\hline Raízen S.A. & 4.494 .466 .039 & 13,24 \\
\hline Odebrecht Agroindustrial S.A. & 4.291 .461 .207 & 12,64 \\
\hline São Martinho S.A. & 1.944 .086 .199 & 5,73 \\
\hline Logum Logística S.A. & 1.758 .600 .000 & 5,18 \\
\hline Rumo Logística S.A. & 1.633 .832 .432 & 4,81 \\
\hline Brenco & 1.390 .653 .206 & 4,10 \\
\hline Cocal Comércio de Açúcar e Álcool LTDA & 1.302 .553 .000 & 3,84 \\
\hline Copersucar S.A. & 1.266 .600 .000 & 3,73 \\
\hline
\end{tabular}

Fonte: BNDES, 2017

\footnotetext{
9 Foram consideradas como principais, aquelas que juntas receberam $50 \%$ do valor total de financiamentos do BNDES ao setor.
} 
Tabela 2. Financiamento do BNDES para o setor sucroenergético, em milhões de reais, por ano e tipo de investimento (2002-2015)

\begin{tabular}{ccccccccc}
\hline Ano & Total & $\begin{array}{c}\text { Capital } \\
\text { de giro } \\
\mathbf{e} \\
\text { fundos }\end{array}$ & Cogeração Logística & $\begin{array}{c}\text { Operações } \\
\text { Mistas }\end{array}$ & Pesquisa & Plantios & $\begin{array}{c}\text { Usinas e } \\
\text { Infraestruturas }\end{array}$ \\
\hline 2002 & 208,2 & 0 & 171,3 & 0 & 36,8 & 0 & 0 & 0 \\
\hline 2003 & 298,1 & 0 & 152,0 & 66,6 & 79,4 & 0 & 0 & 0 \\
\hline 2004 & 87,8 & 0 & 16,7 & 0 & 49,8 & 0 & 21,2 & 0 \\
\hline 2005 & 419,4 & 0 & 132,7 & 0 & 286,6 & 0 & 0 & 0 \\
\hline 2006 & 799,3 & 0 & 341,2 & 0 & 195,5 & 0 & 30,9 & 231,5 \\
\hline 2007 & $3.141,2$ & 43,9 & 244,4 & 0 & $1.686,7$ & 1,4 & 248,0 & 916,6 \\
\hline 2008 & $4.888,0$ & 0 & 734,0 & 60,0 & $3.505,4$ & 1,5 & 0 & 583,9 \\
\hline 2009 & $4.420,1$ & 0 & 564,3 & 372,5 & $2.523,3$ & 20,5 & 44,2 & 895,0 \\
\hline 2010 & $5.621,2$ & $1.610,0$ & $1.087,1$ & 558,7 & $2.303,8$ & 13,0 & 0 & 61,4 \\
\hline 2011 & $3.569,2$ & 0 & 509,3 & $1.777,2$ & 916,3 & 0 & 0 & 366,2 \\
\hline 2012 & $3.000,0$ & 0 & 205,5 & 194,2 & 922,4 & 0 & 481,1 & $1.196,6$ \\
\hline 2013 & $2.941,1$ & 0 & 0 & 180,4 & 662,8 & 79,5 & $1.033,5$ & 984,6 \\
\hline 2014 & $3.522,6$ & 565,0 & 15,8 & $1.287,8$ & 243,5 & 53,1 & 729,2 & 627,9 \\
\hline 2015 & $1.031,8$ & 20,0 & 80,7 & 0 & 84,8 & 12,6 & 833,6 & 0 \\
\hline Total & $33.948,3$ & $2.238,9$ & $4.255,5$ & $4.500,9$ & $13.497,7$ & 181,9 & $3.422,0$ & $5.864,2$ \\
\hline & & & & 7046,5 & \\
\hline
\end{tabular}

Fonte: BNDES, 2017.

A tabela demonstra o nível significativo de concentração dos financiamentos do BNDES para o setor, em que aproximadamente metade do total de recursos foram direcionados a apenas sete agentes. Dentre as empresas citadas, cinco possuem capital aberto e/ou participam do mercado de bolsas de valores (como a Bolsa de Valores de São Paulo - BM\&FBOVESPA, por exemplo), como a Odebrecht Agroindustrial, a Brenco (inicialmente, um fundo de investimentos), a Cosan (desde 2005, com ações comercializas na BM\&FBOVESPA) e a Cosan LTD (ações comercializadas desde 2007 na New York Stock Exchange - NYSE), sendo as 
últimas duas comandadas pelo grupo Cosan, que também possui o controle da Raízen S.A. e da Rumo Logística (ações na BM\&FBOVESPA). A São Martinho S.A. também negocia ações desde 2007. Além das empresas que aparecem na tabela, a Tereos Internacional S.A. (desde 2007) e a Biosev S.A. (desde 2013), completam a lista das empresas do setor sucroenergético que comercializam ações no mercado de valores.

Ainda no que se refere às empresas que aparecem na tabela 1, é importante destacar a relação das seguintes: a Raízen S.A. e a Rumo Logística S.A (atualmente Rumo ALL), possuem em sua fundação e em sua composição acionária a centralidade do grupo Cosan, cuja direção e fundação estão ligadas à família Ometto (tradicional família de usineiros do interior de São Paulo). A mesma ligação com a família Ometto também é verificada no grupo São Martinho S.A.

Até o ano de 2017, quando levantados os dados no BNDES, a presidência da Cosan era ocupada por Rubens Ometto Silveira Melo e a vice-presidência por Marcos Marinho Luz, ambos também ocupam a presidência da Rumo Logística S.A. Já a São Martinho tinha como presidente João Guilherme Sabino Ometto e como vice-presidente Marcelo Campos Ometto. Juntas, essas empresas receberam aproximadamente $24 \%$ do total de recursos direcionados pelo BNDES para o setor. Trata-se de uma concentração significante dos financiamentos, que por sua vez, é reflexo da concentração das atividades no território e nos grupos empresariais.

A Raízen S.A, joint venture da Royal Dutch Shell e da Cosan, criada em 2010, foi a principal receptora dos investimentos do BNDES no período, concentrando pouco mais de $13 \%$ do total de recursos ( $R \$ 4,5$ bilhões). Os recursos recebidos foram utilizados em projetos diversos, como instalação de centros coletores de etanol, adequação de unidades produtivas para produção de energia a partir de cogeração, expansão da capacidade produtiva através da expansão e/ou modernização das unidades produtivas, plantio de canaviais, reformas e/ou expansão de canaviais já existentes.

A Odebrecht Agroindustrial e a Brenco (Brazilian Renewable Energy Company), respectivamente segundo e sexto lugar no ranking, fazem parte de um mesmo processo de constituição. A fração do grupo Odebrecht que atua no setor sucroenergético surgiu em 2007 com o nome de ETH Bioenergia (ODEBRECHT, 2016) e em 2010 realizou uma fusão com a Brenco, criando uma nova empresa que manteve o mesmo nome (ETH Bioenergia). Por sua vez, a Brenco foi fundada em 
2007 por investidores nacionais e estrangeiros ${ }^{10}$ para atuar como um fundo de investimentos exclusivo para o setor sucroenergético brasileiro.

Com a crise de 2008 e os empecilhos de remuneração dos acionistas, a Brenco buscou alternativas de capitalização, como os empréstimos do BNDES por exemplo (PINTO, 2011, p. 91). Um pouco mais de 4\% dos investimentos do BNDES no período foram direcionados para atuarem como capital de giro para a empresa, mesmo em um contexto em que o BNDESPar figurava como um dos acionistas da Brenco (PINTO, 2011, p. 94; BNDES, 2016). A Brenco foi incluída na lista "suja" do Ministério do Trabalho em 2009, por trabalho análogo ao escravo em usinas do grupo, portanto, antes de sua fusão com a Odebrecht Agroindustrial, e, como consequência, a empresa ficou impedida de acessar linhas de crédito de bancos públicos.

Ainda em 2010 e após a fusão com a Brenco, a Odebrecht e a Sojitz Corporation (empresa japonesa) expandiram seu controle acionário e passaram a deter $65 \%$ da ETH Bioenergia (que passou a se chamar Odebrecht Agroindustrial), enquanto os acionistas da Brenco detiveram 35\% dos ativos (ODEBRECHT, 2016).

Após 2014, a Odebrecht Agroindustrial passou por perdas financeiras e de acionistas (como o Fundo Ashmore e Tarpon), momento em que a Odebrecht ampliou seu controle acionário para 99,98\% da Odebrecht Agroindustrial, com o restante distribuídos entre os acionistas. A empresa passou por uma série de problemas desde então, como a condenação, pela justiça brasileira, por tráfico de pessoas e trabalho análogos ao escravo na construção de uma usina sucroenergética em Angola, na África (FELLET, 2015) e o constante adiamento de suas dívidas com os bancos privados e públicos (GOULART, 2016). Além disso, é preciso ressaltar que após 2015, o grupo Odebrecht se envolveu em escândalos de corrupção, que envolveram inclusive os próprios financiamentos do BNDES.

O contexto que envolve o grupo Odebrecht Agroindustrial permite questionar o engajamento do Estado brasileiro com os agentes privados, que se mantém mesmo quando há acusações graves. A análise sobre essa perspectiva parece

\footnotetext{
${ }^{10}$ Entre os investidores envolvidos na formação da Brenco estavam o ex-presidente da Petrobrás Henri Philippe Reichtul (que iniciou como presidente da Brenco), os fundos de investimentos Khosla Ventures, Yucaipa Companies, Tarpon Investments e Amber Capital, os grupos Semco e Ashmore Energy Internacional, e mais tarde, o banco Goldman Sachs (PINTO, 2011, p. 90), o ex-presidente dos EUA, Bill Clinton, o ex-presidente do Banco Mundial, James D. Wolfesohn e o próprio BNDES através do BNDESPar (HOUTART, 2009, p. 192; SALGADO, 2010).
} 
verificar a condição do Estado como um espaço de disputa de poderes, em que interesses específicos prevalecem e se colocam como prioritários.

A São Martinho S.A, cujo controle principal também é da família Ometto, recebeu, no período, pouco mais de $5 \%$ do total destinado ao setor pelo BNDES, montante este que fora destinado a projetos como adaptação para cogeração de energia e expansão da capacidade produtiva de eletricidade, construção de terminais de estocagem de etanol, ampliação da capacidade de moagem de usinas e modernização industrial, investimentos em fertirrigação, aquisição de máquinas agrícolas e investimentos sociais.

Ainda aparecem no ranking das maiores empresas financiadas, dois agentes relacionados à logística, fator essencial para a fluidez e efetivação do processo produtivo sucroenergético: a Logum S.A e a Rumo Logística S.A.

O projeto da Logum S.A (criada em 2011), que pode ser sintetizado pela construção de um sistema logístico de transporte por dutos para o etanol, é mais que emblemático para a compreensão da forma como a viabilização do território para as atividades do setor é sustentada pelo Estado.

O Sistema Logístico Multimodal de Etanol, idealizado e gerenciado pela Logum, funciona atualmente com oito terminais de estocagem de etanol interligados por dutos e que ligam as principais regiões produtoras aos grandes centros consumidores (LOGUM, 2018). Para além do financiamento subsidiado pelo BNDES, essa primeira etapa do projeto também foi incluída no Programa de Aceleração do Crescimento (PAC 2) do Governo Federal (LOGUM, 2016), com investimento inicial previsto de $R \$ 5,8$ bilhões (TEREZA, 2011). A saber, a composição inicial da Logum S.A compreendia as empresas: Camargo Correa Participações (10\%), Copersucar (20\%), Raízen (20\%), Odebrecht Transport Participações (20\%), Petrobras (20\%) e Uniduto Logística (10\%) (LOGUM, 2016).

Apesar do próprio BNDES justificar os investimentos nos dutos de etanol a partir da necessidade da diminuição de modais onerosos, como o rodoviário por exemplo (MILANEZ et al., 2010, p. 95), a estrutura de criação da Logum já oferece indícios de quais agentes irão se beneficiar, de fato, da fluidez gerada pelo sistema logístico do etanol. Nesse contexto, algo tão necessário para a logística brasileira, que é a diversificação dos modais de transporte, se materializa para um setor específico através de recursos públicos, cuja gestão e captação dos lucros se dará 
na esfera privada de grandes grupos nacionais que centralizam e monopolizam o processo.

A efetivação de um projeto como o do sistema logístico da Logum traz implicações diretas ao território, tal como afirmam Camelini e Castillo (2012, p. 19), isso porque há tendência de intensificação e concentração das atividades nas áreas adjacentes as redes de dutos, que passam a apresentar maior fluidez, criando regiões especializadas e consequentemente, em condições de vulnerabilidade. Essa situação, em última análise, indica a influência que os agentes do setor possuem no jogo de disputa de interesses no âmbito do Estado.

Desse modo, o sistema logístico da Logum é representativo das implicações territoriais das atividades sucroenergéticas, tal como ocorrem atualmente no Brasil, a medida em que reitera um atributo do território brasileiro que é, segundo Santos e Silveira (2001, p. 237), a criação seletiva e desigual de fluidez, através de consolidação de infraestruturas subordinadas a interesses e setores específicos e não necessariamente relacionadas a interesses mais amplos.

Outra empresa do segmento que integra o ranking é a Rumo Logística S.A (que realizou fusão com a América Latina Logística - ALL, em 2014, consolidando a maior operadora de ferrovias do Brasil ${ }^{11}$ ), pertencente ao grupo Cosan. Todos os projetos da Rumo Logística S.A. financiados pelo BNDES são diretamente relacionados ao transporte de açúcar para exportação no porto de Santos-SP.

A representatividade dos investimentos do BNDES em infraestrutura logística, especificamente voltada para as atividades sucroenergéticas, ilustra a importância do Estado para a sustentação do setor. Nesse contexto é importante ressaltar que essas ações são legitimadas pelo discurso do "desenvolvimento" de setores estratégicos em prol do bem comum, que acaba por mascarar um processo de direcionamento massivo de recursos públicos para a esfera privada, sem considerar as implicações ou demandar maiores contrapartidas aos beneficiados. Trata-se de tornar o território funcional à reivindicações específicas de produção, através da norma e da materialidade necessárias para a efetivação da produção competitiva assegurada através de recursos públicos.

\footnotetext{
${ }^{11}$ Após a fusão com a ALL, a Rumo passou a deter 12,9 mil quilômetros de malha ferroviária, 966 locomotivas e 28 mil vagões (ANTT, 2016). É importante ressaltar que a fusão foi aprovada com restrições pelo Conselho Administrativo de Defesa Econômica (CADE), uma vez que houve a preocupação de que concorrentes da Cosan, que utilizam os serviços da ALL, fossem prejudicados (AMATO, 2015).
} 


\section{Considerações Finais}

Os dados analisados revelam a importância da intervenção do Estado brasileiro, tanto para a viabilização do território para as atividades (em aspectos normativos e técnicos essenciais para a esfera produtiva), quanto para sustentação e expansão da produção sucroenergética em patamares competitivos.

No âmbito material, essa viabilização se dá através da consolidação de infraestruturas de transportes, na esfera produtiva, entre outros, enquanto na esfera normativa, se dá através de políticas públicas específicas ao setor, leis que favorecem a produção, a destinação de crédito, dentre outras ações fomentadas pelo Estado. Uma forma particular de atuação do Estado brasileiro na sustentação de agentes privados neste início de século foi, sem dúvida, o acionamento e a instrumentalização do BNDES, o que pode ser observado através dos dados de financiamento do banco no período analisado.

Essas ações do Estado atingem agentes nacionais e estrangeiros que atuam no setor sucroenergético e que em muito se beneficiam de tal situação, o que, inclusive, não se dá de forma homogênea e reitera a concentração das atividades no território e também do capital à um grupo seleto de empresas, produzindo ao mesmo tempo implicações socioespaciais significativas. A consequência para o território é seu enrijecimento, uma vez que a atividade, por suas características intrínsecas (CASTILLO, 2015), possui força centralizadora (da produção, da matéria prima, do controle fundiário, das infraestruturas de logística), o que promove condições de vulnerabilidade a municípios e regiões inteiras.

A análise dos investimentos do BNDES para o setor sucroenergético permitiu compreender a natureza da relação entre Estado e agentes privados no período atual, marcada pela corroboração de práticas corporativas, e, ao mesmo tempo, também permite questionarmos o próprio papel que o Estado desempenha sobre o território. Isso porque, as implicações socioespaciais advindas do processo produtivo sucroenergético estão implicitamente ligadas ao Estado, uma vez que sua sustentação é central para a produção do setor.

Tais questões devem ser consideradas para pensarmos as atividades sucroenergéticas no Brasil após os anos 2000, que se concretizam em concordância a dinâmica global de acumulação de capitais, cada vez mais centrada nas finanças e 
com a integração global de agentes. Nesse contexto, é possível pensar a expansão recente das atividades sucroenergéticas (e de modo implícito, o próprio território brasileiro) como parte de uma estratégia de solução para a crise de superacumulação que assolou o mundo na primeira década do século atual, processo este que, ao que parece, foi amplamente sustentado pelo Estado brasileiro.

Outra questão a ser considerada é o processo de intensificação da estrangeirização do setor sucroenergético após os anos 2000, que ocorre tanto por meio de fusões, aquisições e joint ventures, como também por meio do mercado financeiro. Entre as empresas que compõe esse ranking, apenas a Logum S.A, a Coopersucar e a Cocal Comércio de Açúcar LTDA ${ }^{12}$ não se capitalizam em mercado de bolsa de valores, o que não significa necessariamente ausência de participação de capitais estrangeiros no processo. De todo modo, o que é questionável é a transferência de recursos públicos a empresas que possuem sua lucratividade atrelada a processos especulativos e a ampla participação do Estado na sustentação do setor, tendo em vista as implicações socioterritoriais derivadas dessas atividades.

Obviamente a discussão sobre as implicações territoriais das relações tecidas entre agentes privados e Estado não pode ser esgotada neste trabalho, em que pese a importância da análise para entender as condições postas às atividades sucroenergéticas e aos espaços mais acionados pelo agronegócio brasileiro nesse início de século. Esperamos que as discussões aqui realizadas possam contribuir para uma análise crítica das dinâmicas de uso do território brasileiro no período atual, quando os investimentos corporativos decorrem dos recursos públicos da nação e os benefícios de tal processo se acumulam na esfera privada, comumente legitimados pelos discursos de desenvolvimento, sustentabilidade e progresso.

\section{Referências Bibliográficas}

AMATO, Fábio. CADE aprovada, com restrição, fusão entre ALL e Rumo Logística. G1. Página na internet. Disponível em:

12 Os financiamentos direcionados para a Coopersucar foram utilizados para expansão e modernização das usinas, financiamento de capital de giro e infraestrutura logística para exportação, e a Cocal Comércio de Açúcar LTDA utilizou os recursos em projetos de infraestrutura e cogeração de energia. 
<http://g1.globo.com/economia/negocios/noticia/2015/02/cade-aprova-com-restricao-fusaoentre-all-e-rumo-logistica.html>. Acesso em ago. 2016.

ANDRADE, Manuel Correia de. Formação territorial e econômica do Brasil. Recife: Fundação Joaquim Nabuco, Editora Massangana, 2006. 310 p.

BERNARDES, Adriana et al. O papel ativo da Geografia: um manifesto. São Paulo: Laboplan, 2000.

BNDES - Banco Nacional do Desenvolvimento Econômico e Social. Página na internet. Disponível em: <http://www.bndes.gov.br/>. Acesso entre jun. 2015 e jul. 2016.

BORRAS JR, Saturnino M et al. The rise of flex crops and commodities: implications for research. The Journal of Peasant Studies. v. 29, n. 1, p. 93-115, 2015.

CAMELINI, João Humberto; CASTILLO, Ricardo. Etanol e uso corporativo do território. Mercator. Fortaleza, v. 11, n. 25, p. 7-18, 2012. Disponível em:

$<$ http://www.mercator.ufc.br/index.php/mercator/article/viewFile/722/414 > . Acesso em jul. 2014.

CASTILLO, Ricardo. Dinâmicas recentes do setor sucroenergético no Brasil: competitividade regional e expansão para o bioma cerrado. Geographia, Niterói, v. 17, n. 35, 2015, p. 95119.

CFM - Conselho Federal de Medicina. Saúde apresenta apenas $8 \%$ do total de investimentos públicos no Brasil. Página na Internet. Disponível em $<$ http://portal.cfm.org.br/index.php?option=com content\&view=article\&id=24511: sauderepresenta-so-8-do-total-de-investimentos-publicos-no-brasil\&catid=3>. Acesso em jan. 2016.

DELGADO, Guilherme Costa. Do capital financeiro na agricultura à economia do agronegócio: mudanças cíclicas em meio século (1965-2012). Porto Alegre: UFRGS, 2012.

FARIAS, Hélio Caetano. O papel do BNDES na integração do território brasileiro. Geousp Espaço e Tempo. São Paulo, n. 34, 2013, p. 119-133.

FELLET, João. Juiz condena Odebrecht por trabalho escravo e tráfico de pessoas em Angola. BBC. Página na internet. Disponível em: $<$ http://www.bbc.com/portuguese/noticias/2015/09/150831 odebrecht angola condenacao pai if >. Acesso em dez. 2016.

GENNARI, Adilson Marques. Globalização, neoliberalismo e abertura econômica no Brasil nos anos 1990. Pesquisa\&Debate. São Paulo, v. 13, n. 1(21), 2002, p. 30-45. Disponível em: <http://revistas.pucsp.br/index.php/rpe/article/view/12029>. Acesso em abr. 2015.

GOULART, Josette. Odebrecht Agroindustrial renegocia dívida de R 7 bilhões. Revista Exame. São Paulo, 2016. Página na internet. Disponível em: $<$ http://exame.abril.com.br/negocios/odebrecht-agroindustrial-reestrutura-divida-de-r-7bilhoes/>. Acesso em jan. 2017.

HARVEY, David. Dezessete contradições e o fim do capitalismo. São Paulo: Boitempo, 2016.

HARVEY, David. Neoliberalismo. Histórias e implicações. São Paulo: Loyola. 2008. 
HOUTART, François. La agroenergia: solución para el clima o salida de la crisis para el capital. Havana: Ruth Casa Editorial, 2009.

KAHIL, Samira Peduti. Psicoesfera: uso corporativo da esfera técnica do território e o novo espirito do capitalismo. Sociedade \& Natureza. Uberlândia, 2010. v. 22, n. 3. Disponível em: < http://www.seer.ufu.br/index.php/sociedadenatureza/article/view/11332>. Acesso em fev. 2015.

LOGUM - Página na internet. Disponível em: < http://www.logum.com.br/php/index.php $>$. Acesso em out. 2016.

MILANEZ, Artur Yabe et al. Logística para o etanol: situação atual e desafios futuros. BNDES Setorial, Brasília, n. 31, p. 49-98, mar. 2010. Disponível em: <https://web.bndes.gov.br/bib/jspui/handle/1408/2407>. Acesso em jul. 2016.

ODEBRECHT. ETH e Brenco anunciam fusão de ativos. Página na internet. Disponível em: < http://www.odebrecht.com/pt-br/comunicacao/releases/eth-e-brenco-anunciam-fusaode-ativos $>$ Acesso em dez. 2016.

OLIVEIRA, Francisco de Oliveira. Crítica à razão dualista: o ornitorrinco. Boitempo: São Paulo, 2003.

PINTO, Mairun Junqueira Alves. Investimentos diretos estrangeiros no setor sucroenergético. 2011. 174 f. Tese (Doutorado) - Curso de Administração, Universidade de São Paulo, Ribeirão Preto, 2011. Disponível em:

$<$ http://www.teses.usp.br/teses/disponiveis/96/96132/tde-17012012-

152314/publico/MairunJAPinto Original.pdf>. Acesso em 12 nov. 2016.

RUMO ALL - Rumo América Latina Logística. Página na internet. Disponível em. $<$ http://pt.rumolog.com/default pti.asp?idioma=0\&conta=45>. Acesso em out. 2016.

SALGADO, Eduardo. Brenco capta 80 milhões de dólares. Revista Exame, São Paulo, 2010. Página na internet. Disponível em: < http://exame.abril.com.br/negocios/brenco-capta80-milhoes-de-dolares-m0152627/>. Acesso em dez. 2016.

SANTOS. Milton. Natureza do espaço: técnica e tempo, razão e emoção. São Paulo: Editora da Universidade de São Paulo, 2012.

SANTOS, Milton; SILVEIRA, Maria. Laura. O Brasil: território e sociedade no início do século XXI. Rio de Janeiro: Best Bolso, 2011.

SÃO MARTINHO - Página na internet. Disponível em: <http://www.saomartinho.ind.br/>Acesso em nov. 2016.

SIDRA/IBGE - Sistema de Recuperação Automática IBGE. Página na internet. Disponível em: $\leq$ http://www.sidra.ibge.gov.br/> Acesso em ago. 2015.

SILVA, Laís Ribeiro. O BNDES e a sustentação do setor sucroenergético no Brasil: implicações territoriais no contexto neoliberal e de financeirização. 2017. $152 \mathrm{f}$. Dissertação (Mestrado em Geografia) -Instituto de Geografia, Universidade Federal de Uberlândia, Uberlândia. 2017. Disponível em: https://repositorio.ufu.br/handle/123456789/18930> Acesso em jan. 2019.

SZMRECSÁNYI, Tamás. O planejamento da agroindústria canavieira do Brasil (1930 1975). Campinas: Hucitec; Unicamp, 1979. 
TEIXEIRA, Francisco José Soares (org.). Neoliberalismo e reestruturação produtiva: as novas determinações do mundo do trabalho. Ceará: Cortez, 1998. p. 195-252.

TEIXEIRA, Rodrigo Alves; PINTO, Eduardo Costa. Economia política dos governos FHC, Lula e Dilma: dominância financeira, bloco no poder e desenvolvimento econômico.

Economia e Sociedade, Campinas, v. 21, Número Especial, p. 909-941, dez. 2012.

TEREZA, Irany. BNDES emprestará R \$ 5,8 bi à Logum Logística. Estado de São Paulo. (jornal). Caderno Negócios. 2011. Disponível em:

$<$ http://economia.estadao.com.br/noticias/negocios,bndes-emprestara-r-5-8-bi-a-logumlogistica,86199e >. Acesso em: jul. 2014.

VEGA, Gerardo Enrique Cerdas; RODRIGUEZ, Maria Helena. As prioridades do BNDES: financiamento para o desenvolvimento? In: CARDOSO, Alessandra; BORGES, Caio de Souza; RODRIGUEZ, Maria Helena (org.). A política ambiental do BNDES: presente e futuro. Brasília: Athalaia, 2015.

\section{NOTAS DE AUTOR}

\section{CONTRIBUIÇÃO DE AUTORIA}

Laís Ribeiro Silva - Concepção, Coleta e organização de dados, Análise de dados, elaboração do manuscrito e revisões.

Mirlei Fachini Vicente Pereira - Participação ativa na análise dos dados e dos resultados, na elaboração do manuscrito e revisão da versão final do trabalho.

\section{FINANCIAMENTO}

O texto resulta de pesquisa realizada no Programa de Pós-Graduação em Geografia da Universidade Federal de Uberlândia, com apoio financeiro (bolsa) do CNPq-Brasil.

\section{CONSENTIMENTO DE USO DE IMAGEM}

Não se aplica.

\section{APROVAÇÃO DE COMITÊ DE ÉTICA EM PESQUISA}

Não se aplica.

\section{CONFLITO DE INTERESSES}

Não se aplica.

\section{LICENÇA DE USO}

Este artigo está licenciado sob a Licença Creative Commons CC-BY. Com essa licença você pode compartilhar, adaptar, criar para qualquer fim, desde que atribua a autoria da obra.

\section{HISTÓRICO}

Recebido em: 30-01-2019

Aprovado em: 11-02-2019 